\title{
Photodynamic therapy: A hot topic in dermato-oncology (Review)
}

\author{
MIRCEA TAMPA $^{1}$, MARIA-ISABELA SARBU ${ }^{1}$, CLARA MATEI $^{1}$, CRISTINA-IULIA MITRAN $^{2}$, \\ MADALINA-IRINA MITRAN ${ }^{2}$, CONSTANTIN CARUNTU ${ }^{3}$, CAROLINA CONSTANTIN ${ }^{4}$, \\ MONICA NEAGU ${ }^{4}$ and SIMONA-ROXANA GEORGESCU ${ }^{1}$ \\ ${ }^{1}$ Department of Dermatology, 'Carol Davila' University of Medicine and Pharmacy, 020021 Bucharest; \\ ${ }^{2}$ Department of Dermatology, 'Victor Babes' Hospital, 030303 Bucharest; ${ }^{3}$ Department of Physiology, \\ 'Carol Davila' University of Medicine and Pharmacy, 020021 Bucharest; ${ }^{4}$ Department of Immunology, \\ 'Victor Babes', National Institute of Pathology, 050096 Bucharest, Romania
}

Received August 20, 2018; Accepted December 7, 2018

DOI: $10.3892 / 01.2019 .9939$

\begin{abstract}
Photodynamic therapy (PDT) is a modern, non-invasive therapeutic method used for the destruction of various cells and tissues. It requires the simultaneous presence of three components: a photosensitizer (PS), a light source and oxygen. Precancerous skin lesions are conditions associated with a high likelihood of malignant transformation to squamous cell carcinoma. Data available so far indicate that PDT is a promising treatment method which can be successfully employed in several medical fields including dermatology, urology, ophthalmology, pneumology, cardiology, dentistry and immunology. Numerous authors therefore have studied this technique in order to improve its efficacy. As a result, significant advancement has been achieved with regard to PSs and drug delivery systems. Substantial progress was also obtained with respect to PDT for the treatment of precancerous skin lesions, several authors focusing their efforts on the study
\end{abstract}

Correspondence to: Dr Maria-Isabela Sarbu, Department of Dermatology, 'Carol Davila' University of Medicine and Pharmacy, 37 Dionisie Lupu Street, 020021 Bucharest, Romania

E-mail: isabela_sarbu@yahoo.com

Abbreviations: PDT, photodynamic therapy; ROS, reactive oxygen species; AK, actinic keratosis; SCC, squamous cell carcinoma; PS, photosensitizer; ${ }^{3} \mathrm{O}_{2}$, triplet oxygen; $\mathrm{O}^{2-}$, superoxide anion; $\mathrm{OH}$, hydroxyl radical; ${ }^{1} \mathrm{O}_{2}$, singlet oxygen; $\mathrm{HpD}$, hematoporphyrin derivative; ALA, 5-aminolevulinic acid; MAL, methyl aminolaevulinate; PpIX, protoporphyrin IX; UCNPs, upconversion nanoparticles; NIR, near infrared; MRI, magnetic resonance imaging; c-PDT, conventional photodynamic therapy; D-PDT, daylight photodynamic therapy; HAL, hexylaminolaevulinate, RCM, reflectance confocal microscopy; BD, Bowen's disease; EQ, erythroplasia of Queyrat; 5-FU, 5-fluorouracil; HPV, human papilloma virus; Er:YAG AFL, erbium:yttrium-aluminium-garnet ablative fractional laser; AC, actinic cheilitis; LS, lichen sclerosus

Key words: photodynamic therapy, precancerous lesions, squamous cell carcinoma, actinic keratosis, actinic cheilitis of daylight-PDT and on identifying methods of decreasing technique-related pain. This review reports on the most recent findings in PDT, with emphasis on cutaneous precancerous lesions.

\section{Contents}

1. Introduction

2. Photodynamic therapy - generalities

3. Updates in PDT components

4. Updates in PDT for the management of actinic keratoses

5. Updates in PDT for Bowen's disease and erythroplasia of Queyrat

6. Updates in PDT in the treatment of other precancerous skin lesions: Actinic cheilitis and keratoacanthoma

7. Updates in PDT for lichen sclerosus - a dermatosis with potential for malignant transformation

8. Discussion

\section{Introduction}

Photodynamic therapy (PDT) is a relatively new, non-invasive therapeutic method used for the destruction of various cells and tissues consisting in the administration of a photosensitizing drug followed by irradiation of light and generation of reactive oxygen species (ROS) which lead to cell death. It has been employed in several medical fields including dermatology, urology, ophthalmology, pneumology, cardiology, dentistry and immunology (1-4). Moreover, antimicrobial and antiviral PDT have been found useful for the treatment of various infectious diseases, water sterilization and inactivation of pathogens in blood products, among others (1).

Precancerous skin lesions are conditions associated with a high likelihood of malignant transformation to squamous cell carcinoma $(5,6)$. The lesions may exhibit increased mitotic rate, abnormal mitotic figures, nuclear pleomorphism or abnormal differentiation (6). Some of the lesions, such as actinic keratoses (AK), have minimal atypia, while others, such as Bowen's disease, are in situ squamous cell carcinomas (SCCs) (6). 
The most important risk factors involved in the development of precancerous skin lesions are exposure to UV radiation, immunosuppression, fair skin type and genetic predisposition (7-15).

\section{Photodynamic therapy - generalities}

PDT requires the simultaneous presence of three components: a photosensitizer (PS), a light source and oxygen (16). The PS preferentially accumulates in tumor cells and in macrophages. When the PS is exposed to light of specific wavelength it becomes activated to the short-live (nanoseconds) excited singlet state. This state can decay to the ground state or it can undergo intersystem crossing to the long-live (microseconds) triplet state. The PS in the triplet state interacts with the surrounding molecules through two types of reactions. In type I reactions, either a hydrogen atom is abstracted, or an electron is transferred between the substrate and the PS and free radicals are produced. In type II reactions, the PS interacts with molecular oxygen, also known as triplet oxygen $\left({ }^{3} \mathrm{O}_{2}\right)$, and produces ROS, including superoxide anion $\left(\mathrm{O}_{2}^{--}\right)$, hydroxyl radical $(\mathrm{OH})$ and singlet oxygen $\left({ }^{1} \mathrm{O}_{2}\right)(4,17,18)$. ROS, especially singlet anion, are very harmful for the surrounding cells and are responsible for the destructive effects of PDT (16). Depending on factors such as type and dose of PS, localization of PS, intensity and wavelength of light and oxygen concentration (19), PDT induces cell death through autophagy, apoptosis or cellular necrosis $(1,16,19,20)$.

The history of PDT is long and marked by several important events. Even though ancient civilizations already knew that various plants could be combined with sunlight to treat skin diseases like vitiligo and psoriasis $(21,22)$, the rediscovery and mechanism elucidation of PDT only occurred at the beginning of the 20th century (23). In 1900, Raab and von Tappeiner first observed an in vitro photodynamic effect and in 1904 von Tappeiner coined the term 'photodynamic' (24,25). In 1903 Niels Finsen was awarded the Nobel Prize for his contribution to the treatment of lupus vulgaris with concentrated light radiation $(26,27)$ and in 1929 Hans Fischer received the Noble Prize for the examination of porphyrins (26). The discovery of hematoporphyrin derivative (HpD) in 1960 by Lipson et al (28) and photofrin by Dougherty et al are also key moments in the history of PDT $(26,29)$.

Since PDT showed promising results in several medical fields, the subject captured the interest of numerous authors in recent years and extensive research was carried out in the attempt to improve the method. Our objective is to look over the most recent findings in PDT, with emphasis on cutaneous precancerous lesions.

\section{Updates in PDT components}

As mentioned before, PDT requires the presence of three components: light, PS and oxygen. A wide range of light sources can be used for PDT, including light emitting diodes, lasers and fluorescent lamps (30). Blue light is preferred for the maximum absorbance while red and infrared radiations best penetrate the tissues. However, only light up to $800 \mathrm{~nm}$ can generate singlet oxygen. The light source should be chosen based on PS absorption, disease characteristics and costs $(30,31)$.

Several agents have been developed and studied in the attempt to identify ideal PS. Hematoporphyrin derivative and photofrin are first generation PSs. They have several limitations, including a complex composition and low light absorption rate (26). Hence, there was a real need to identify new PS. The second-generation PS were therefore developed. Most have a cyclic tetrapyrrolic structure and are represented by porphyrins and porphyrin analogs, chlorins, bacteriochlorins, phthalocyanines and metallo-phthalocyanines (1,32-35). 5-Aminolevulinic acid (ALA), a biological precursor of protoporphyrin IX (PpIX) and its methylated ester, methyl aminolaevulinate (MAL), have been widely used in dermatology (30). Mono-L-aspartyl chlorin e6 (NPe6), temoporfin and hexylpyropheophorbide (HPPH) have a chlorin structure and have been used in head and neck cancer, bile duct cancer, brain cancer, lung cancer and sarcoma (31). Secondgeneration PS are pure compounds, are well absorbed in the range of 650-800 $\mathrm{nm}$ and are less toxic than first generation PS. However, the degree of selectivity for the target tissue and the insufficient depth of treatment are the main limitations of these agents $(1,4)$.

Third generation PS are currently being developed to improve PDT outcomes. Nanotechnology in PDT and gene engineering mediated PDT are therefore intensely researched (26). Nanomedicine is the medical application of nanotechnology and it uses nanomaterials which can improve drug delivery to target area, can improve drug solubility, can minimize degradation and increase drug bioavailability, among others $(4,36,37)$. Nanoparticles can be used as PS, they can help deliver PS by conjugation with antibodies, folate, transferrin or antibodies against the transferrin receptor or can be used as energy transducers $(1,4)$. PS can be encapsulated in liposomes to improve tumor-selective accumulation (38), in micelles to resist elimination by the reticuloendothelial system $(39,40)$, but also in gold nanoparticles $(41-43)$, biodegradable polymer-based nanoparticles, quantum dots (18) carbon nanoparticles and silica nanoparticles $(4,17,44)$.

Nanotheranostics is a new medical field which combines the diagnostic and therapeutic capabilities into one nanoplatform (45). Theranostic nanoparticles could have a great impact on cancer management and could make personalized medicine possible (45-49). Nanoparticles used in nanotheranostics could therefore carry both anticancer agents and imaging probes such as MRI contrast agents to tumors or they could simultaneously deliver multiple therapeutic agents such as chemotherapy and PDT (45).

Upconversion nanoparticles (UCNPs) are a new generation of fluorophores which can convert long wavelength radiation, like near infrared (NIR) light into visible radiation or ultraviolet (UV) light through non-linear optical processes (50). NIR light has the advantage that it can penetrate deeper into tissues but it has the disadvantage that it cannot generate cytotoxic singlet oxygen. UCNPs can absorb NIR light and emit visible radiation which can initiate PS activation (18). Chen et al developed a UCNP $\left(\mathrm{NaYF}_{4}: \mathrm{Yb}^{3+} / \mathrm{Er}^{3+} / \mathrm{Tm}^{3+}\right)$-based micelle capable of NIR-controlled combination chemotherapy and PDT and fluorescent imaging for the treatment of neuroendocrine tumors and found that UCNP-based micelle exhibited 
Table I. Summary of the studies supporting the efficacy of daylight photodynamic therapy in precancerous skin lesions.

\begin{tabular}{llrlll}
\hline Lesion & Photosensitizer & No. of patients & \multicolumn{1}{c}{ Study design } & \multicolumn{1}{c}{ Results } & Refs. \\
\hline AK & MAL & 100 & D-PDT vs. c-PDT & Similar efficacy & $(63)$ \\
AK & MAL & 35 & D-PDT vs. c-PDT & Similar efficacy for AK I & $(64)$ \\
AK & MAL & 646 & D-PDT vs. c-PDT & D-PDT more effective than c-PDT & $(65)$ \\
AK & MAL & 26 & D-PDT vs. c-PDT & Equal prevention against NMSC & $(66)$ \\
AK & MAL & 46 & D-PDT vs. c-PDT & Similar long-term efficacy & $(67)$ \\
AK & BF-200 ALA, & 13 & BF-200 ALA D-PDT & BF-200 ALA more effective & $(68)$ \\
& MAL & & vs. MAL-D-PDT & than MAL & $(69)$ \\
AK & MAL, HAL & 13 & HAL D-PDT vs. MAL D-PDT & Similar long-term efficacy & $(72)$ \\
AK & MAL & 22 & D-PDT vs. ingenol mebutate gel & Similar efficacy & $(98)$ \\
AC & MAL & 2 & Case study D-PDT & Efficacious & $(99)$ \\
AC & MAL & 10 & D-PDT observational study & Complete response in 5/10 patients & after 12 months \\
& & & & & \\
\hline
\end{tabular}

AK, actinic keratosis; AC, actinic cheilitis; BF-200 ALA, nanoemulsion formulation with $10 \%$ aminolaevulinic acid hydrochloride; c-PDT, conventional photodynamic therapy; D-PDT, daylight photodynamic therapy; HAL, hexylaminolaevulinate; MAL, methyl aminolevulinate; NMSC, non-melanoma skin cancer.

excellent imaging capabilities, induced a better antitumor efficacy than PDT and chemotherapy alone and could be a promising nanoplatform for neuroendocrine tumor theranostics (45). Other authors also showed that UCNPs $\left(\mathrm{NaGdF}_{4}: \mathrm{Yb} /\right.$ $\mathrm{Tm})$ developed as folic acid (FA)-targeted $\mathrm{NaGdF}_{4}: \mathrm{Yb} / \mathrm{Tm} @$ $\mathrm{SiO}_{2} @ \mathrm{TiO}_{2}$ nanocomposites have potential applications in both magnetic resonance imaging (MRI) and NIR-responsive PDT (51).

\section{Updates in PDT for the management of actinic keratoses}

AK, also known as solar keratoses, are some of the most common skin lesions (8). AKs typically appear on sun-exposed areas in fair skinned individuals and clinically present as erythematous, flat, scaly papules which can range from a few millimetres to a few centimetres in diameter $(5,52)$. Several treatment options are available for AK, including cryosurgery, curettage, laser ablation, diclofenac gels, dermabrasion, imiquimod, 5-fluorouracil and PDT. Surgical excision is recommended when malignant transformation to SCC is suspected (5-8).

ALA-PDT and MAL-PDT have both been licensed for the treatment of AK (strength of recommendation A, quality of evidence I according to the European guidelines for topical PDT, 2013), the typical clearance rate being 89-92\% (30). The treatment is more efficacious for face and scalp lesions than for acral lesions (30).

The use of PDT for the treatment of field cancerization has been recently studied by several authors. Field cancerization represents the existence of subclinical lesions adjacent to the clinically apparent lesions. It is now considered that the treatment of AK alone is not sufficient and that the field of cancerization must be targeted (53). Passos et al aimed to explore the outcome of PDT treatment using a nanoformulation of ALA (nano-ALA) in patients with field cancerization and to compare the results with those obtained with MAL-PDT. The authors found that the efficacy of nano-ALA-PDT is higher than the efficacy of MAL-PDT in treating field cancerization (54).

In a randomized, double blind, phase III multicentre study published in 2016, the efficacy and safety of BF-200 ALA, a nanoemulsion formulation with $10 \%$ aminolaevulinic acid hydrochloride, was compared with placebo in the field-directed treatment of mild-to-moderate actinic keratosis with PDT using the BF-RhodoLED lamp. BF-200 ALA was found superior to placebo with respect to complete clearance rate and complete lesion rate and the authors concluded that field-directed therapy with BF-200 ALA and BF-RhodoLED lamp is effective and well tolerated (55).

PDT was also compared with other treatment methods available for AK and field cancerization. Daylight MAL-PDT was found more cosmetically acceptable and was associated with a superior tolerability profile when compared to ingenol mebutate (56). MAL-PDT and imiquimod 5\% cream were found equally effective in preventing the occurrence of new AKs in patients with field cancerization (57). ALA-PDT showed better clinical results than $35 \%$ trichloroacetic acid peel in the treatment of patients with field cancerization (58) and microneedling-assisted PDT was found to produce superior cosmetic results for improving photoaged skin as compared to MAL-PDT (59).

Daylight PDT (D-PDT) for AK is still a hot topic (Table I). Even though conventional PDT (c-PDT) showed very good results, the method presents some inconvenience e.g., long incubation period and adverse reactions such as burning, stinging or pain (60). D-PDT uses visible light to activate the PS and is therefore more cost-effective and less time-consuming $(60,61)$. D-PDT is mostly recommended for non-hyperkeratotic lesions located on sun exposed areas like the face and the scalp and light exposure should begin within 30 min of applying the PS. Sunscreen without physical blocking filters is necessary to protect from UV damage $(60,62)$. Several authors compared 
the efficacy of D-PDT to that of c-PDT. In a randomized, investigator-blinded, controlled study, adult patients were treated with MAL D-PDT on one side of the face and MAL c-PDT on the other side of the face. After 12 weeks, $70 \%$ of the patients treated with D-PDT and $74 \%$ of those treated with c-PDT showed complete response. D-PDT was nearly painless and better tolerated than c-PDT (63). Fargnoli et al also evaluated the efficacy and tolerability of D-PDT and c-PDT with MAL in patients with $\mathrm{AK}$ and found that, after 3 months of treatment, there were no significant differences in complete response rates between the two methods $(87 \%$ for D-PDT vs. $91 \%$ for c-PDT) in patients with grade I AK, D-PDT however being less effective in the treatment of grade II and grade III AK (64). In a retrospective study performed on 406 patients with AK treated with c-PDT and 240 patients with AK treated with D-PDT the authors reported superior efficacy of D-PDT and concluded that D-PDT may be routinely used to treat multiple AKs for aesthetic purposes (65). The safety and efficacy of D-PDT and c-PDT in the prevention of occurrence of new non-melanoma skin cancer in patients with field cancerization was also studied and findings suggest that D-PDT and c-PDT have equal preventive potential (66). Longterm efficacy, safety and tolerability of D-PDT and c-PDT were evaluated in an intra-individual right-left comparison study. At the 3-month follow-up, $80.6 \%$ of patients treated with c-PDT and $78 \%$ of those treated with D-PDT had complete lesion remission while at the 12-month follow-up $71.8 \%$ of patients treated with D-PDT and $73.7 \%$ of patients treated with c-PDT had complete remission. Grade II lesions responded better to c-PDT while D-PDT had a better tolerability profile (67).

New PS agents were also studied in an attempt to improve D-PDT. In a double-blind, split face prospective study, 13 patients with 177 AKs were randomized to receive BF-200 ALA or MAL D-PDT. After 3 months, $84.5 \%$ of lesions treated with BF-ALA D-PDT and $74.2 \%$ of lesions treated with MAL D-PDT cleared (68). After 12 months, BF-200 ALA D-PDT showed better maintained clearance than MAL D-PDT, the authors therefore concluding that BF-200 ALA shows improved efficacy compared with MAL (69). Hexylaminolaevulinate (HAL) is a long-chained ester of ALA which has better skin penetration than MAL. Neittaanmäki et al compared the long-term efficacy of D-PDT with $0.2 \% \mathrm{HAL}$ with that of $16 \%$ MAL and concluded that HAL and MAL have similar efficacies and that the use of low doses of HAL could help reduce treatment costs $(70)$.

When compared to other treatment options for AK, D-PDT with MAL showed significantly better results than diclofenac plus hyaluronic acid gel (71) and similar results with ingenol mebutate gel (72). Calcipotriol pre-treatment prior to D-PDT showed improved efficacy as compared to D-PDT alone. Erythema and desquamation, however, are more frequent in patients pre-treated with calcipotriol, patients therefore preferring D-PDT alone (73). Pre-treatment with 5-FU cream, however, was shown to increase the efficacy of D-PDT without significantly increasing erythema and pain (74).

Since D-PDT requires dry and warm weather condition, there is some concern that the availability of D-PDT might be limited by the meteorological conditions. A study performed in Australia showed that D-PDT can be used throughout the year if weather conditions permit (75). Artificial white light
LED PDT seems to be an effective, well tolerated alternative (76) and could be performed when D-PDT is not available.

Some authors aimed at identifying diagnostic techniques which could help assess the efficacy of D-PDT (77-79). Seyed Jafari et al used reflectance confocal microscopy (RCM) to evaluate AK lesions before and after D-PDT and found that $\mathrm{RCM}$ features of AK correlate with the results of the clinical evaluation and could therefore be used to monitor the efficacy of D-PDT (78). de Souza et al measured PpIX fluorescence, STAT3 cross-linking and keratinocyte damage in the skin of nude mice exposed to daylight and low-light PDT. The researchers found a strong correlation between PpIX-weighted light dose and STAT3 cross-linking and between PpIXweighted light dose and keratinocyte damage (79).

\section{Updates in PDT for Bowen's disease and erythroplasia of Queyrat}

Bowen's disease (BD) is SCC in situ of the skin. Erythroplasia of Queyrat (EQ) is SCC of the mucous membranes $(5,52)$. BD most often affects men and women older than 60 years and is generally located on sun exposed areas. It clinically presents as an erythematous, well-demarcated scaly patch or plaque with irregular borders. Rarely, the lesions may be pigmented. Sun exposure, ionizing radiation, immunosuppression and HPV infection are the most important risk factors for developing BD (5,7,80-83). EQ most often affects uncircumcised men between the ages of 30 and 60 years (5). Clinically, it presents as a well demarcated, shiny, velvety erythematous plaque typically located on the penis, vulva, perianal area or mouth (50). Poor hygiene, local trauma, lack of circumcision and HPV infection are the most important risk factors for developing EQ (5). The treatment options available for BD and EQ are surgical excision, Mohs micrographic surgery, curettage, electrodessication, laser ablation, cryosurgery, topical 5-FU and $\operatorname{PDT}(5,52)$.

PDT is very efficient for the treatment of BD (strength of recommendation A, quality of evidence I) according to the European guideline for topical PDT (30), MAL-PDT being associated with $86-93 \%$ clearance of lesions.

Previous studies showed that ALA-PDT can be used in combination with surgery, imiquimod and radiotherapy for the treatment of BD with very good results $(84,85)$. Ablative Carbon Dioxide $\left(\mathrm{CO}_{2}\right)$ Fractional Laser pre-treatment and erbium:yttrium-aluminium-garnet ablative fractional laser (Er:YAG AFL) were also used in combination with PDT for treating BD. Kim et al found that $50 \%$ of lesions pre-treated with ablative $\mathrm{CO}_{2}$ fractional laser completely responded to three PDT sessions and that after four sessions, $90 \%$ of the lesions completely cleared (86). Similar results were reported by other authors (87). Ko et al compared the recurrence rate, cosmetic outcomes and safety of MAL-PDT to those of Er:YAG AFL-assisted MAL-PDT (Er:YAG AFL-PDT) in 21 patients with $58 \mathrm{BD}$ lesions. The authors found that Er:YAG AFL-PDT was significantly more effective than MAL-PDT, it showed lower recurrence rate and had similar cosmetic outcomes (88).

Even though there is sufficient evidence supporting the effectiveness of topical PDT for the treatment of BD, some authors showed that large $\mathrm{BD}$, with more than $10 \mathrm{~cm}$ in diam- 
eter, might not be suitable candidates for this method. The authors therefore suggest that a cut-off value of size must be established (89).

PDT also showed promising results for the treatment of EQ (90). Studies therefore showed that $62.5 \%$ of patients treated with MAL-PDT and $58.3 \%$ of patients treated with ALA-PDT achieved complete remission (91).

\section{Updates in PDT in the treatment of other precancerous skin lesions: Actinic cheilitis and keratoacanthoma}

Actinic cheilitis (AC) is a premalignant keratosis of the lip (6) most often affecting fair-skinned people who are exposed to UV radiation (7). It is often considered a form of $\mathrm{AK}$ located on the lips (5). In the early stages the disease presents as erythematous, scaly papules or plaques with fissures and sometimes erosions affecting the lower lip. In more advanced stages patients present grey-white plaques and sometimes warty nodules $(5,6)$. Several treatment options are available, including vermilionectomy, 5-FU, diclofenac gel, laser ablation, PDT and trichloroacetic acid (6).

A systematic review published in 2015, which included 15 case series with 242 patients, found that $62 \%$ of patients treated with PDT for AC showed complete remission at final follow-up and that $47 \%$ of the patients evaluated for histological outcome showed histological cure at final follow-up. The authors therefore concluded that PDT has the potential to clinically and histologically treat AC (92).

ALA-patch PDT was also tried in the treatment of AC. The patch has the advantage of standardized delivery of ALA. A study performed on 11 patients with $15 \mathrm{AC}$ lesions reported complete remission in 8 of 11 patients and 12 of 15 lesions at the 3-months follow-up. After 1 year, 10 of 15 lesions showed complete clinical cure, the cosmetic result being excellent (93).

Since some studies found that PDT is not an efficacious treatment for AC $(94,95)$, some authors aimed at finding new methods to improve this technique. Fontes et al evaluated the efficacy of MAL-PDT with previous application of $\mathrm{CO}_{2}$ laser in eight patients with $\mathrm{AC}$ of the lower lip. $\mathrm{CO}_{2}$ laser has the advantage that it allows a better distribution and absorption of the PS. The authors reported clinical improvement in all patients and histopathological improvement of the epithelial dysplasia in $66.6 \%$ of patients (96). Other authors compared the efficacy of Er:YAG AFL MAL-PDT with that of two sessions of standard MAL-PDT in 33 patients with histologically confirmed AC. At the 3-month follow-up, the authors found a complete response rate in $92 \%$ of patients receiving Er:YAG AFL MAL-PDT and $59 \%$ of patients receiving MAL-PDT. After 12 months, 85\% of patients treated with Er:YAG AFL MAL-PDT and 29\% of those treated with MAL-PDT had complete response rate. The authors concluded that pre-treatment with ablative fractional laser brings significant benefit to PDT for AC (97).

Some good results were found with D-PDT for the treatment of $\mathrm{AC}(98,99)$. Fai et al treated 10 patients with refractory AC of the lower lip with D-PDT with MAL and obtained complete response in seven patients at 3 months after therapy and five patients at 6-12 months after therapy (99).

Keratoacanthoma is considered by some authors a variant of SCC and by other authors a benign tumor (7). It is characterized by rapid growth and a tendency towards spontaneous regression (5). It typically appears on sun exposed regions. Several variants have been described, including solitary keratoacanthoma, multiple keratoacanthomas, giant keratoacanthoma, keratoacanthoma centrifugum marginatum, generalized eruptive keratoacanthomas of Grzbowski and multiple keratoacanthomas of the Ferguson-Smith type (5). Numerous treatment options are available for keratoacanthoma, including PDT. The data regarding the use of PDT for keratoacanthomas is however scarce and limited to case presentations or case series. While some authors show that PDT could be a good alternative for patients with keratoacanthomas $(100,101)$, other authors suggest that keratoacanthomas could develop after PDT $(102,103)$. Further research is therefore mandatory to support the usefulness of PDT for the treatment of keratoacanthomas.

\section{Updates in PDT for lichen sclerosus - a dermatosis with potential for malignant transformation}

Lichen sclerosus (LS) is a chronic, inflammatory disease which can affect both anogenital and extragenital regions (7). Genital LS appears in women as white, atrophic, pruritic lesions on the vulva, labia minora, clitoris and introitus and in men as white, atrophic patches, usually non-pruritic, on the prepuce (52). Genital LS is not intrinsically a precancerous condition, but it is associated with chronic scarring which promotes carcinogenesis (7). Halonen et al studied the risk of cancer of female patients with genital LS on data from the Finnish Cancer Registry and found that LS is associated with an increased risk of vulvar and vaginal cancer (104). Various treatment options are available for genital LS, including topical glucocorticosteroids, topical calcineurin inhibitors, systemic glucocorticosteroids, oral retinoids, methotrexate and phototherapy, among others (105). Circumcision is a good therapeutic option for male genital lichen sclerosus. According to the Evidence-based (S3) Guideline on (anogenital) Lichen sclerosus published in 2015, PDT can be considered for the treatment of vulvar LS if standard treatment has failed (105).

Shi et al compared the effectiveness and adverse reactions of clobetasol propionate, the conventional treatment of vulvar LS, with those of ALA-PDT, in 40 patients with vulvar LS. The authors found that ALA-PDT was associated with a higher complete response rate and longer remission duration than clobetasol propionate and concluded that ALA-PDT is a well-tolerated treatment option for vulvar LS (106).

The effectiveness and safety of PDT for the treatment of vulvar LS were studied by several authors. In a study performed on ten patients with refractory vulvar LS, nine out of ten patients reported improved clinical response and complete disappearance of itching and one patient reported decrease of itching from severe to mild. Side effects were pain, swelling and erythema and were tolerable (107). Another study performed on 102 patients with vulvar LS treated with ALA-PDT weekly for ten weeks found complete and partial response in $87.25 \%$ of patients, the greatest response being observed in the reduction of subepithelial ecchymoses and telangiectasia (108). Olejek et al also reported significant attenuation in intensity of symptoms in patients treated with ALA-PDT for LS with or without concomitant autoimmune 
disease. The level of antinuclear antibodies also significantly decreased, the authors therefore concluding that PDT might also influence the immune status of the patients (109). MAL-PDT was also used in the treatment of nine patients with genital LS with good results (110).

Considering that procedure-related pain is an important adverse effect which limits the patients' adherence to treatment (111), some authors aimed their research at finding alternatives in order to decrease pain and avoid treatment discontinuation $(112,113)$. Cabete et al reported good pain control after using inhaled nitrous oxide/oxygen gas mixture during MAL-PDT for vulvar LS. ALA-PDT with green light was also used in 11 patients with vulvar LS associated with severe itching. The authors reported significant improvement in local status, reduction of pruritus and good treatment tolerance, none of the patients requiring treatment cessation or topical analgesics (112).

Since circumcision is an effective therapeutic option for penile LS, the data regarding the usefulness of PDT for this condition in men is scarce. In a recent study, however, Mercuri et al showed that a combination of $1927 \mathrm{~nm}$ thulium fiber laser and MAL-PDT was effective in two patients with recalcitrant LS of the penis (114). Further research is however required to establish real effectiveness.

\section{Discussion}

PDT is a modern therapeutic method which has captured the interest of several authors in recent years. The advances in the development and use of PSs and drug delivery systems are remarkable. With regard to PDT for the treatment of precancerous skin lesions, several authors focused their research on assessing the effectiveness of D-PDT and identifying methods of decreasing technique-related pain. Since data available so far indicate that PDT is a promising treatment in several medical fields, it is expected that further research will be performed in order to improve the efficacy of the technique.

\section{Acknowledgements}

Not applicable.

\section{Funding}

No funding was received.

\section{Availability of data and materials}

The datasets used and/or analyzed during the current study are available from the corresponding author on reasonable request.

\section{Authors' contributions}

MT, MIS and CM were responsible for writing the manuscript, editing, acquisition, analysis and interpretation of the data. CIM and MIM contributed to data acquisition, software assistance and editing references. $\mathrm{CoC}, \mathrm{CaC}, \mathrm{MN}$ and $\mathrm{SRG}$ contributed to the conception and design of the study and were involved in critical revision of the manuscript. All authors read and approved the final manuscript.

\section{Ethics approval and consent to participate}

Not applicable.

\section{Patient consent for publication}

Not applicable.

\section{Competing interests}

The authors declare that they have no competing interests.

\section{References}

1. Benov L: Photodynamic therapy: Current status and future directions. Med Princ Pract 24 (Suppl 1): 14-28, 2015.

2. Braathen LR, Morton CA, Basset-Seguin N, Bissonnette R, Gerritsen MJ, Gilaberte Y, Calzavara-Pinton P, Sidoroff A, Wulf HC and Szeimies RM; International Society for Photodynamic Therapy in Dermatology: Photodynamic therapy for skin field cancerization: An international consensus. J Eur Acad Dermatol Venereol 26: 1063-1066, 2012.

3. Matei C, Tampa M, Caruntu C, Ion RM, Georgescu SR, Dumitrascu GR, Constantin C and Neagu M: Protein microarray for complex apoptosis monitoring of dysplastic oral keratinocytes in experimental photodynamic therapy. Biol Res 47: 33, 2014

4. Paszko E, Ehrhardt C, Senge MO, Kelleher DP and Reynolds JV: Nanodrug applications in photodynamic therapy. Photodiagn Photodyn Ther 8: 14-29, 2011.

5. Goldsmith LA, Katz SI, Gilchrest BA, Paller AS, Leffell DJ and Wolff K: Epidermal and appendageal tumors. In: Fitzpatrick's Dermatology in General Medicine. 8th edition. McGrawHill, New York, pp1007-1094, 2012.

6. Quinn AG and Perkins W: Non-melanoma skin cancer and other epidermal skin tumours. In: Rook's Textbook of Dermatology. 8th edition. Wiley Blackwell, UK, pp52-53, 2010.

7. Soyer HP, Rigel DS and Wurm EMT: Actinic keratosis, basal cell carcinoma and squamous cell carcinoma. In: Dermatology. 3rd edition. Elsevier, Philadelphia, pp1773-1793, 2012.

8. Sterry W and Stockfleth E: Malignant epithelial tumors: In: Braun-Falco's Dermatology. 3rd edition. Springer-Verlag, Berlin, Heidelberg, pp1357-1376, 2009.

9. Neagu M, Caruntu C, Constantin C, Boda D, Zurac S, Spandidos DA and Tsatsakis AM: Chemically induced skin carcinogenesis: Updates in experimental models (Review). Oncol Rep 35: 2516-2528, 2016.

10. Tampa M, Caruntu C, Mitran M, Mitran C, Sarbu I, Rusu LC, Matei C, Constantin C, Neagu M and Georgescu SR: Markers of oral lichen planus malignant transformation. Dis Markers 2018: 1959506, 2018. doi: 10.1155/2018/1959506.

11. Georgescu SR, Sârbu MI, Matei C, Ilie MA, Caruntu C, Constantin C, Neagu M and Tampa M: Capsaicin: Friend or foe in skin cancer and other related malignancies? Nutrients 9: 1365, 2017.

12. Costescu M, Coman OA, Tampa M, Tudose I, Coman L and Georgescu SR: Axillary basal cell carcinoma - a rare form of a frequent kind of carcinoma. Rom J Morphol Embryol 54 (Suppl): 851-856, 2013.

13. Ene (Nicolae) CD: Nicolae I, Musetescu A, Tampa M, Matei C and Georgescu SR: Exposure to heavy metals in plastics industry and dyes-risk factor in the development of skin cancer. Mater Plast 51: 180-184, 2014.

14. Georgescu SR, Ene CD, Nicolae IL, Mitran M, Musetescu A, Matei C, Rusu LC and Tampa M: Reflectometric analysis for identification of various pathological conditions associated with lichen planus. Rev Chim 68: 1103-1108, 2017.

15. Caruntu C, Mirica A, Roca AE, Mirica R, Caruntu A, Tampa M, Matei C, Constantin C, Neagu M, Badarau A, et al: The role of estrogens and estrogen receptors in melanoma development and progression. Acta Endocrinol (Copenh) 12: 234-241, 2016.

16. Matei C, Tampa M, Poteca T, Panea-Paunica G, Georgescu SR, Ion RM, Popescu SM and Giurcaneanu C: Photodynamic therapy in the treatment of basal cell carcinoma. J Med Life 6: 50-54, 2013. 
17. Shibu ES, Hamada M, Murase N and Biju V: Nanomaterials formulations for photothermal and photodynamic therapy of cancer. J Photochem Photobiol Photochem Rev 15: 53-72, 2013.

18. Chitgupi U, Qin Y and Lovell JF: Targeted nanomaterials for phototherapy. Nanotheranostics 1: 38-58, 2017.

19. Park CK, Kim YH, Hwangbo S and Cho H: Photodynamic therapy by conjugation of cell-penetrating peptide with fluorochrome. Int J Nanomed 12: 8185-8196, 2017.

20. Nicolae I, Ene CD, Georgescu SR, Tampa M, Matei C and Ceausu E: Effects of UV radiation and oxidative DNA adduct 8-hydroxy-2'-deoxyguanosine on the skin diseases. Rev Chim-Bucharest 65: 1036-1041, 2014.

21. Rkein AM and Ozog DM: Photodynamic therapy. Dermatol Clin 32: 415-425, 2014.

22. Sârbu MI, Georgescu SR, Tampa M, Sârbu AE and Simionescu O Biological therapies in psoriasis - revisited. Rom J Intern Med 56 75-84, 2018.

23. Denis TG and Hamblin MR: History and fundamentals of photodynamic therapy. In: Handbook of Photomedicine. 1st edition. CRC Press, Boca Raton, USA, pp35-42, 2014.

24. Raab O: On the effect of fluorescent substances on infusoria. Z Biol 39: 524, 1900

25. Hönigsmann $\mathrm{H}$ : History of phototherapy in dermatology. Photochem Photobiol Sci 12: 16-21, 2013.

26. Kou J, Dou D and Yang L: Porphyrin photosensitizers in photodynamic therapy and its applications. Oncotarget 8: 81591-81603, 2017.

27. Gøtzsche PC: Niels Finsen's treatment for lupus vulgaris. J R Soc Med 104: 41-42, 2011

28. Lipson RL and Baldes EJ: The photodynamic properties of a particular hematoporphyrin derivative. Arch Dermatol 82: 508-516, 1960

29. Dougherty TJ: Photodynamic therapy (PDT) of malignant tumors. Crit Rev Oncol Hematol 2: 83-116, 1984.

30. Morton CA, Szeimies RM, Sidoroff A and Braathen LR: European guidelines for topical photodynamic therapy part 1: Treatment delivery and current indications - actinic keratoses, Bowen's disease, basal cell carcinoma. J Eur Acad Dermatol Venereol 27: 536-544, 2013.

31. Agostinis P, Berg K, Cengel KA, Foster TH, Girotti AW, Gollnick SO, Hahn SM, Hamblin MR, Juzeniene A, Kessel D, et al: Photodynamic therapy of cancer: An update. CA Cancer J Clin 61: 250-281, 2011.

32. Tampa M, Matei CL, Popescu SA, Georgescu SR, Neagu MO, Constantin $\mathrm{C}$ and Ion RM: Zinc trisulphonated phthalocyanine used in photodynamic therapy of dysplastic oral keratinocytes. Rev Chim 64: 639-645, 2013

33. Matei C, Tampa M, Ion RM, Neagu M and Constantin C: Photodynamic properties of aluminium sulphonated phthalocyanines in human displazic oral keratinocytes experimental model. Dig J Nanomater Biostruct 7: 1535-1547, 2012.

34. Neagu M, Constantin C, Tampa M, Matei C, Lupu A, Manole E, Ion RM, Fenga $\mathrm{C}$ and Tsatsakis AM: Toxicological and efficacy assessment of post-transition metal (Indium) phthalocyanine for photodynamic therapy in neuroblastoma. Oncotarget 7 : 69718-69732, 2016

35. Neagu M, Manda G, Constantin C, Radu E and Ion RM: Synthetic porphyrins in experimental photodynamic therapy induce a different antitumoral effect. J Porphyr Phthalocyanines 11: $58-65,2007$.

36. Boda D: Cellomics as integrative omics for cancer. Curr Proteomics 10: 237-245, 2013.

37. Caruntu C, Boda D, Dumitrascu G, Constantin C and Neagu M: Proteomics focusing on immune markers in psoriatic arthritis Biomarkers Med 9: 513-528, 2015.

38. Derycke AS and de Witte PA: Liposomes for photodynamic therapy. Adv Drug Deliv Rev 56: 17-30, 2004.

39. Li B, Moriyama EH, Li F, Jarvi MT, Allen C and Wilson BC: Diblock copolymer micelles deliver hydrophobic protoporphyrin IX for photodynamic therapy. Photochem Photobiol 83: $1505-1512,2007$.

40. Zhang GD, Harada A, Nishiyama N, Jiang DL, Koyama H, Aida T and Kataoka K: Polyion complex micelles entrapping cationic dendrimer porphyrin: Effective photosensitizer for photodynamic therapy of cancer. J Control Release 93: 141-150, 2003.

41. Hone DC, Walker PI, Evans-Gowing R, FitzGerald S, Beeby A, Chambrier I, Cook MJ and Russell DA: Generation of cytotoxic singlet oxygen via phthalocyanine-stabilized gold nanoparticles: A potential delivery vehicle for photodynamic therapy. Langmuir 18: 2985-2987, 2002.
42. Wieder ME, Hone DC, Cook MJ, Handsley MM, Gavrilovic J and Russell DA: Intracellular photodynamic therapy with photosensitizer-nanoparticle conjugates: Cancer therapy using a 'Trojan horse'. Photochem Photobiol Sci 5: 727-734, 2006

43. Haimov E, Weitman H, Polani S, Schori H, Zitoun D and Shefi O meso-Tetrahydroxyphenylchlorin-conjugated gold nanoparticles as a tool to improve photodynamic therapy. ACS Appl Mater Interfaces 10: 2319-2327, 2018

44. Brezániová I, Záruba K, Králová J, Sinica A, Adámková H, Ulbrich P, Poučková P, Hrubý M, Stěpánek P and Král V: Silica-based nanoparticles are efficient delivery system for temoporfin. Photodiagn Photodyn Ther 21: 275-284, 2018.

45. Chen G, Jaskula-Sztul R, Esquibel CR, Lou I, Zheng Q, Dammalapati A, Harrison A, Eliceiri KW, Tang W, Chen H, et al: Neuroendocrine tumor-targeted upconversion nanoparticle-based micelles for simultaneous NIR-controlled combination chemotherapy and photodynamic therapy, and fluorescence imaging. Adv Funct Mater 27: 1604671, 2017.

46. Luo Y, Wu H, Feng C, Xiao K, Yang X, Liu Q, Lin TY, Zhang H, Walton JH, Ajena Y, et al: 'One-Pot' fabrication of highly versatile and biocompatible poly(vinyl alcohol)-porphyrin-based nanotheranostics. Theranostics 7: 3901-3914, 2017.

47. Engin AB, Nikitovic D, Neagu M, Henrich-Noack P, Docea AO, Shtilman MI, Golokhvast K and Tsatsakis AM: Mechanistic understanding of nanoparticles' interactions with extracellular matrix: The cell and immune system. Part Fibre Toxicol 14: 22 , 2017.

48. Neagu M and Boda D: Transcriptomics in cancer-stages toward patents in biomarkers? Recent Pat Biomark 2: 75-82, 2012.

49. Tampa M, Matei C, Caruntu C, Poteca T, Mihaila D, Paunescu C, Pitigoi G, Georgescu SR, Constantin C and Neagu M: Cellular impedance measurement - novel method for in vitro investigation of drug efficacy. Farmacia 64: 430-434, 2016.

50. Wang M, Abbineni G, Clevenger A, Mao C and Xu S: Upconversion nanoparticles: Synthesis, surface modification and biological applications. Nanomedicine (Lond) 7: 710-729, 2011.

51. Zhang L, Zeng L, Pan Y, Luo S, Ren W, Gong A, Ma X, Liang H, $\mathrm{Lu} \mathrm{G}$ and $\mathrm{Wu} \mathrm{A}$ : Inorganic photosensitizer coupled Gd-based upconversion luminescent nanocomposites for in vivo magnetic resonance imaging and near-infrared-responsive photodynamic therapy in cancers. Biomaterials 44: 82-90, 2015.

52. Sterry W, Paus R, Burgdorf W and Holtermann H: Carcinoma in situ: In: Thieme Clinical Companions Dermatology. Stuttgart, New York, pp417-419, 2006.

53. Hofbauer G, Anliker M, Boehncke WH, Brand C, Braun R, Gaide O, Hafner J, Hunger R, Itin P, Kaeuper G, et al: Swiss clinical practice guidelines on field cancerization of the skin. Swiss Med Wkly 144: w14026, 2014.

54. Passos SK, de Souza PE, Soares PK, Eid DR, Primo FL, Tedesco AC, Lacava ZG and Morais PC: Quantitative approach to skin field cancerization using a nanoencapsulated photodynamic therapy agent: A pilot study. Clin Cosmet Investig Dermatol 6: 51-59, 2013

55. Reinhold U, Dirschka T, Ostendorf R, Aschoff R, Berking C, Philipp-Dormston WG, Hahn S, Lau K, Jäger A, Schmitz B, et al: A randomized, double-blind, phase III, multicentre study to evaluate the safety and efficacy of BF-200 ALA (Ameluz(®) vs. placebo in the field-directed treatment of mild-to-moderate actinic keratosis with photodynamic therapy (PDT) when using the BF-RhodoLED(®) lamp. Br J Dermatol 175: 696-705, 2016.

56. Genovese G, Fai D, Fai C, Mavilia L and Mercuri SR: Daylight methyl-aminolevulinate photodynamic therapy versus ingenol mebutate for the treatment of actinic keratoses: An intraindividual comparative analysis. Dermatol Ther (Heidelb) 29: 191-196, 2016.

57. Sotiriou E, Apalla Z, Vrani F, Lallas A, Chovarda E and Ioannides D: Photodynamic therapy vs. imiquimod $5 \%$ cream as skin cancer preventive strategies in patients with field changes: A randomized intraindividual comparison study. J Eur Acad Dermatol Venereol 29: 325-329, 2015.

58. Holzer G, Pinkowicz A, Radakovic S, Schmidt JB and Tanew A: Randomized controlled trial comparing $35 \%$ trichloroacetic acid peel and 5-aminolaevulinic acid photodynamic therapy for treating multiple actinic keratosis. Br J Dermatol 176: 1155-1161, 2017.

59. Torezan L, Chaves Y, Niwa A, Sanches JA Jr, Festa-Neto C and Szeimies RM: A pilot split-face study comparing conventional methyl aminolevulinate-photodynamic therapy (PDT) with microneedling-assisted PDT on actinically damaged skin. Dermatol Surg 39: 1197-1201, 2013. 
60. See JA, Shumack S, Murrell DF, Rubel DM, Fernández-Peñas P, Salmon R, Hewitt D, Foley P and Spelman L: Consensus recommendations on the use of daylight photodynamic therapy with methyl aminolevulinate cream for actinic keratoses in Australia. Australas J Dermatol 57: 167-174, 2016.

61. Wiegell SR, Haedersdal M, Philipsen PA, Eriksen P, Enk CD and Wulf HC: Continuous activation of PpIX by daylight is as effective as and less painful than conventional photodynamic therapy for actinic keratoses; a randomized, controlled, single-blinded study. Br J Dermatol 158: 740-746, 2008.

62. Griffin LL and Lear JT: Photodynamic therapy and non-melanoma skin cancer. Cancers (Basel) 8: 98, 2016.

63. Lacour JP, Ulrich C, Gilaberte Y, Von Felbert V, Basset-Seguin N, Dreno B, Girard C, Redondo P, Serra-Guillen C, Synnerstad I, et al: Daylight photodynamic therapy with methyl aminolevulinate cream is effective and nearly painless in treating actinic keratoses: A randomised, investigator-blinded, controlled, phase III study throughout Europe. J Eur Acad Dermatol Venereol 29: 2342-2348, 2015.

64. Fargnoli MC, Piccioni A, Neri L, Tambone S, Pellegrini C and Peris K: Conventional vs. daylight methyl aminolevulinate photodynamic therapy for actinic keratosis of the face and scalp: An intra-patient, prospective, comparison study in Italy. J Eur Acad Dermatol Venereol 29: 1926-1932, 2015.

65. Cantisani C,Paolino G, Bottoni U and Calvieri S: Daylight-photodynamic therapy for the treatment of actinic keratosis in different seasons. J Drugs Dermatol 14: 1349-1353, 2015.

66. Sotiriou E, Apalla Z, Vrani F, Lazaridou E, Vakirlis E, Lallas A and Ioannides D: Daylight photodynamic therapy vs. conventional photodynamic therapy as skin cancer preventive treatment in patients with face and scalp cancerization: An intra-individual comparison study. J Eur Acad Dermatol Venereol 31: 1303-1307, 2017.

67. Sotiriou E, Evangelou G, Papadavid E, Apalla Z, Vrani F, Vakirlis E, Panagiotou M, Stefanidou M, Pombou T, Krasagakis $\mathrm{K}$, et al: Conventional vs. daylight photodynamic therapy for patients with actinic keratosis on face and scalp: 12-month follow-up results of a randomized, intra-individual comparative analysis. J Eur Acad Dermatol Venereol 32: 595-600, 2018

68. Neittaanmäki-Perttu N, Karppinen TT, Grönroos M, Tani TT and Snellman E: Daylight photodynamic therapy for actinic keratoses: A randomized double-blinded nonsponsored prospective study comparing 5-aminolaevulinic acid nanoemulsion (BF-200) with methyl-5-aminolaevulinate. Br J Dermatol 171: 1172-1180, 2014.

69. Neittaanmäki-Perttu N, Grönroos M, Tani T and Snellman E: Long-term outcome of daylight photodynamic therapy with amino-5-laevulinate nanoemulsion vs. methyl-5-aminolaevulinate for actinic keratoses. Acta Derm Venereol 96: 712-713, 2016.

70. Neittaanmäki-Perttu N, Karppinen TT, Tani T, Snellman E and Grönroos M: Long-term outcome of low-concentration Hexyl-5aminolaevulinate daylight photodynamic therapy for treatment of actinic keratoses. Acta Derm Venereol 97: 120-121, 2017.

71. Calzavara-Pinton P, Zane C, Pacou M and Szeimies RM: Bucher's indirect comparison of daylight photodynamic therapy with methyl aminolevulinate cream versus diclofenac plus hyaluronic acid gel for the treatment of multiple actinic keratosis. Eur J Dermatol 26: 487-492, 2016.

72. Moggio E, Arisi M, Zane C, Calzavara-Pinton I and Calzavara-Pinton P: A randomized split-face clinical trial analyzing daylight photodynamic therapy with methyl aminolaevulinate vs ingenol mebutate gel for the treatment of multiple actinic keratoses of the face and the scalp. Photodiagn Photodyn Ther 16: 161-165, 2016

73. Galimberti GN: Calcipotriol as pretreatment prior to daylightmediated photodynamic therapy in patients with actinic keratosis: A case series. Photodiagn Photodyn Ther 21: 172-175, 2018.

74. Nissen CV, Heerfordt IM, Wiegell SR, Mikkelsen CS and Wulf HC: Pretreatment with 5-fluorouracil cream enhances the efficacy of daylight-mediated photodynamic therapy for actinic keratosis. Acta Derm Venereol 97: 617-621, 2017.

75. Spelman L, Rubel D, Murrell DF, See JA, Hewitt D, Foley P, Salmon R, Kerob D, Pascual T, Shumack S, et al: Treatment of face and scalp solar (actinic) keratosis with daylight-mediated photodynamic therapy is possible throughout the year in Australia: Evidence from a clinical and meteorological study. Australas J Dermatol 57: 24-28, 2016.
76. O'Gorman SM, Clowry J, Manley M, McCavana J, Gray L, Kavanagh A, Lally A and Collins P: Artificial white light vs daylight photodynamic therapy for actinic keratoses: A randomized clinical trial. JAMA Dermatol 152: 638-644, 2016.

77. Diaconeasa A, Boda D, Neagu M, Constantin C, Căruntu C, Vlădău L and Guţu D: The role of confocal microscopy in the dermato-oncology practice. J Med Life 4: 63-74, 2011.

78. Seyed Jafari SM, Timchik T and Hunger RE: In vivo confocal microscopy efficacy assessment of daylight photodynamic therapy in actinic keratosis patients. Br J Dermatol 175: 375-381, 2016.

79. de Souza ALR, LaRochelle E, Marra K, Gunn J, Davis SC, Samkoe KS, Chapman MS, Maytin EV, Hasan T and Pogue BW: Assessing daylight \& low-dose rate photodynamic therapy efficacy, using biomarkers of photophysical, biochemical and biological damage metrics in situ. Photodiagn Photodyn Ther 20: 227-233, 2017.

80. Lupu M, Caruntu A, Caruntu C, Papagheorghe LML, Ilie MA, Voiculescu V, Boda D, Constantin C, Tanase C, Sifaki M, et al: Neuroendocrine factors: The missing link in non-melanoma skin cancer (Review). Oncol Rep 38: 1327-1340, 2017.

81. Boda D, Docea AO, Calina D, Ilie MA, Caruntu C, Zurac S, Neagu M, Constantin C, Branisteanu DE, Voiculescu V, et al: Human papilloma virus: Apprehending the link with carcinogenesis and unveiling new research avenues (Review). Int J Oncol 52: 637-655, 2018

82. Dinu LU, Ene CD, Nicolae IL, Tampa M, Matei CL and Georgescu SR: The serum levels of 8-hidroxy-deoxyguanosine under the chemicals influence. Rev Chim 65: 1319-1326, 2014.

83. Nicolae I, Tampa M, Mitran C, Ene CD, Mitran M, Matei C, Musetescu A, Pituru S, Pop CS and Georgescu SR: Gamma-glutamyl transpeptidase alteration as a biomarker of oxidative stress in patients with human papillomavirus lesions following topical treatment with sinecatechins. Farmacia 65 : 617-623, 2017.

84. Lucena SR, Salazar N, Gracia-Cazaña T, Zamarrón A, González S, Juarranz Á and Gilaberte Y: Combined treatments with photodynamic therapy for non-melanoma skin cancer. Int J Mol Sci 16: 25912-25933, 2015.

85. Victoria-Martínez AM, Martínez-Leborans L, Ortiz-Salvador JM and Pérez-Ferriols A: Treatment of Bowen disease with photodynamic therapy and the advantages of sequential topical imiquimod. Actas Dermosifiliogr 108: e9-e14, 2017.

86. Kim SK, Park JY, Song HS, Kim YS and Kim YC: Photodynamic therapy with ablative carbon dioxide fractional laser for treating Bowen disease. Ann Dermatol 25: 335-339, 2013.

87. Sung JM and Kim YC: Photodynamic therapy with epidermal ablation using fractional carbon-dioxide laser in the treatment of Bowen's disease: A case series. Photodiagn Photodyn Ther 19: 84-85, 2017.

88. Ko DY, Kim KH and Song KH: A randomized trial comparing methyl aminolaevulinate photodynamic therapy with and without Er:YAG ablative fractional laser treatment in Asian patients with lower extremity Bowen disease: results from a 12-month follow-up. Br J Dermatol 170: 165-172, 2014.

89. Park JY, Kim SK, Cho KH and Kim YC: Huge Bowen's disease: A pitfall of topical photodynamic therapy. Photodiagn Photodyn Ther 10: 546-548, 2013

90. Skroza N, LA Viola G, Pampena R, Proietti I, Bernardini N, Tolino E, Annetta A, Zuber S, Balduzzi V and Potenza C: Erythroplasia of Queyrat treated with methyl aminolevulinate-photodynamic therapy (MAL-PDT): Case report and review of the literature. G Ital Dermatol Venereol: Dec 1, 2016 (Epub ahead of print).

91. Maranda EL, Nguyen AH, Lim VM, Shah VV and Jimenez JJ: Erythroplasia of Queyrat treated by laser and light modalities: A systematic review. Lasers Med Sci 31: 1971-1976, 2016.

92. Yazdani Abyaneh MA, Falto-Aizpurua L, Griffith RD and Nouri K: Photodynamic therapy for actinic cheilitis: A systematic review. Dermatol Surg 41: 189-198, 2015.

93. Radakovic S and Tanew A: 5-aminolaevulinic acid patch-photodynamic therapy in the treatment of actinic cheilitis. Photodermatol Photoimmunol Photomed 33: 306-310, 2017.

94. Da Costa Fontes KBF, Leite TC, Cunha KSG, De Oliveira Miranda AM, Issa MCA, Kurachi C and Dias EP: Clinical and histopathological outcomes of one session of photodynamic therapy for actinic cheilitis. Oral Surg Oral Med Oral Pathol Oral Radiol 117: e201, 2014. 
95. Chaves YN, Torezan LA, Lourenco SV and Neto CF: Evaluation of the efficacy of photodynamic therapy for the treatment of actinic cheilitis. Photodermatol Photoimmunol Photomed 33: 14-21, 2017

96. Fontes KB, Leite TC, Miranda AM, Issa MC, Dias EP, Kurachi C, da Silva LE and Cunha KG: Clinical and histopathological outcomes of one session of photodynamic therapy with previous $\mathrm{CO}_{2}$ laser application for actinic cheilitis. Photodiagn Photodyn Ther 12: 338, 2015.

97. Choi SH, Kim KH and Song KH: Efficacy of ablative fractional laser-assisted photodynamic therapy for the treatment of actinic cheilitis: 12-month follow-up results of a prospective, randomized, comparative trial. Br J Dermatol 173: 184-191, 2015.

98.Levi A, Wulf HC and Enk CD: Two cases of actinic cheilitis responsive to daylight-activated photodynamic therapy (DA-PDT). Photodermatol Photoimmunol Photomed 29: 268-271, 2013

99. Fai D, Romanello E, Brumana MB, Fai C, Vena GA, Cassano N and Piaserico S: Daylight photodynamic therapy with methylaminolevulinate for the treatment of actinic cheilitis. Dermato Ther (Heidelb) 28: 355-368, 2015.

100.Farias MM,Hasson A, Navarrete C, Nick las C, Garcia-Huidobro I and Gonzalez S: Efficacy of topical photodynamic therapy for keratoacanthomas: A case-series of four patients. Indian J Dermatol Venereol Leprol 78: 172-174, 2012.

101. Mlacker S, Kaw U and Maytin EV: Use of photodynamic therapy and acitretin in generalized eruptive keratoacanthoma of Grzybowski. JAAD Case Rep 3: 457-459, 2017.

102. Maydan E, Nootheti PK and Goldman MP: Development of a keratoacanthoma after topical photodynamic therapy with 5-aminolevulinic acid. J Drugs Dermatol 5: 804-806, 2006.

103. Gogia R, Grekin RC and Shinkai K: Eruptive self-resolving keratoacanthomas developing after treatment with photodynamic therapy and microdermabrasion. Dermatol Surg 39: 1717-1720, 2013.

104. Halonen P, Jakobsson M, Heikinheimo O, Riska A, Gissler M and Pukkala E: Lichen sclerosus and risk of cancer. Int J Cancer 140: 1998-2002, 2017.

105. Kirtschig G, Becker K, Günthert A, Jasaitiene D, Cooper S, Chi CC, Kreuter A, Rall KK, Aberer W, Riechardt S, et al: Evidence-based (S3) guideline on (anogenital) Lichen sclerosus. J Eur Acad Dermatol Venereol 29: e1-e43, 2015.
106. Shi L, Miao F, Zhang LL, Zhang GL, Wang PR, Ji J, Wang XJ, Huang Z, Wang HW and Wang XL: Comparison of 5-aminolevulinic acid photodynamic therapy and clobetasol propionate in treatment of vulvar lichen sclerosus. Acta Derm Venereol 96: 684-688, 2016.

107. Lan T, Zou Y, Hamblin MR and Yin R: 5-Aminolevulinic acid photodynamic therapy in refractory vulvar lichen sclerosus et atrophicus: Series of ten cases. Photodiagn Photodyn Ther 21: 234-238, 2018

108. Maździarz A, Osuch B, Kowalska M, Nalewczyńska A and Spiewankiewicz B: Photodynamic therapy in the treatment of vulvar lichen sclerosus. Photodiagn Photodyn Ther 19: 135-139, 2017.

109. Olejek A, Gabriel I, Bilska-Janosik A, Kozak-Darmas I and Kawczyk-Krupka A: ALA-Photodynamic treatment in Lichen sclerosus - clinical and immunological outcome focusing on the assesment of antinuclear antibodies. Photodiagn Photodyn Ther 18: 128-132, 2017.

110. Criscuolo AA, Schipani C, Cannizzaro MV, Messinese S, Chimenti S, Piccione E and Saraceno R: New therapeutic approaches in the treatment of anogenital lichen sclerosus: does photodynamic therapy represent a novel option? G Ital Dermatol Venereol 152: 117-121, 2017

111. Tampa M, Sârbu MI, Mitran MI, Mitran CI, Dumitru A, Benea V and Georgescu SR: Pain in photodynamic therapy. J Mind Med Sci 3: 19-30, 2016

112. Cabete J, Campos S and Lestre S: Conscious sedation with inhaled $50 \%$ nitrous oxide/oxygen premix in photodynamic therapy sessions for vulvar lichen sclerosus treatment. An Bras Dermatol 90: 120-122, 2015 .

113. Osiecka BJ, Jurczyszyn K, Nockowski P, Murawski M and Ziółkowski P: Photodynamic therapy with green light for the treatment of vulvar lichen sclerosus - preliminary results. Photodiagn Photodyn Ther 17: 185-187, 2017.

114. Mercuri SR, Brianti P, Foti A, Bartolucci M, Dattola A and Nisticò SP: Penile lichen sclerosus treated with $1927 \mathrm{~nm}$ thulium fiber laser and photodynamic therapy: A new possible therapeutic approach. Photomed Laser Surg 36: 333-336, 2018. 